\title{
EXAMINING SLEEP AS A PROTECTIVE MECHANISM FOR EXECUTIVE FUNCTIONING IN CHILDREN FROM LOW-INCOME HOMES
}

\author{
Thesis Submitted to \\ The College of Arts and Sciences of the \\ UNIVERSITY OF DAYTON
}

\author{
In Partial Fulfillment of the Requirements for \\ The Degree of \\ Master of Arts in Clinical Psychology
}

By

Sara Elizabeth Wetter

UNIVERSITY OF DAYTON

Dayton, Ohio

August, 2018 
EXAMINING SLEEP AS A PROTECTIVE MECHANISM FOR EXECUTIVE FUNCTIONING IN CHILDREN FROM LOW-INCOME HOMES

Name: Wetter, Sara Elizabeth

APPROVED BY:

Mary Fuhs, Ph.D.

Faculty Advisor

Assistant Professor, Department of Psychology

Jackson Goodnight, Ph.D.

Committee Member

Associate Professor, Department of Psychology

Keri Kirschman, Ph.D.

Committee Member

Associate Professor, Department of Psychology

Lee Dixon. Ph.D.

Associate Professor; Chair, Department of Psychology 


\begin{abstract}
EXAMINING SLEEP AS A PROTECTIVE MECHANISM FOR EXECUTIVE FUNCTIONING IN CHILDREN FROM LOW-INCOME HOMES
\end{abstract}

Name: Wetter, Sara Elizabeth

University of Dayton

Advisor: Dr. Mary Fuhs

For young children, sleep is essential for healthy development across a wide variety of areas. Inadequate sleep can affect emotional, behavioral, cognitive, and health outcomes in early childhood, and can lead to poor outcomes later in life. Low family income and resources can put children at risk for poor sleep quality, impairing their subsequent cognitive abilities, particularly those related to executive functioning. While sleep in early childhood and its effects on executive functioning have been studied, the interaction between family income and sleep habits and their associations with cognitive functioning is less well known.

The current study examined sleep quality as a protective factor against the negative effects of low socioeconomic status (SES) on children's executive functioning skills, specifically those of working memory and inhibition. It was hypothesized that SES would moderate the association between children's sleep quality and executive functioning such that children from low-SES homes would display worse executive 
functioning skills when experiencing poor sleep quality. This study examined these associations by drawing from a large data set collected for a preschool expansion project in the Midwest. Parents filled out surveys related to their children's sleep habits (quality and quantity) and executive functioning, as well as demographics questionnaires determining family income, children's age, and gender.

Poor sleep quality and low family income were associated with poorer performances in both working memory and inhibition. The association between sleep quality and working memory was specific to children from low-SES homes. Exploratory analyses revealed that sleep length was not associated with either working memory or inhibition. Additionally, sleep quality and family income were not associated with a direct assessment of executive functioning. These results suggest that good sleep quality could buffer against poor executive functioning skills for children from low-SES homes. Future studies should attempt to measure these associations longitudinally so as to determine causal links between these variables. 


\section{ACKNOWLEDGEMENTS}

I would like to offer my sincerest thanks to everyone who assisted me in completing my thesis. I appreciate my thesis advisor, Dr. Mary Fuhs, more than I can express, for allowing me to work with and learn from her while doing important research I am passionate about. Her patient assistance throughout this process has been affirming and invaluable, and it has truly been my privilege to undergo this task under her guidance. I would also like to thank my thesis committee members, Dr. Jackson Goodnight and Dr. Keri Kirschman, for their discerning and helpful comments throughout this process and for being willing to hear my defense during their busy summers with their families. Without the aid and support of these committee members, my completion of a well-executed and well-written thesis would not be possible.

Furthermore, I thank everyone who assisted me through this journey in any way. Your encouragement and unyielding support have been instrumental to my completion of this thesis; for that and so much more, I am immensely and eternally grateful.

This work has been supported in part by the University of Dayton Office for Graduate Academic Affairs through the Graduate Student Summer Fellowship. 


\section{TABLE OF CONTENTS}

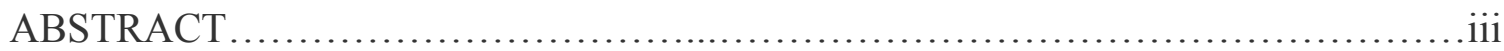

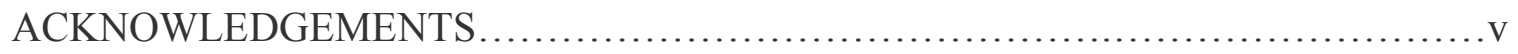

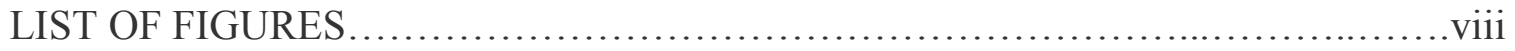

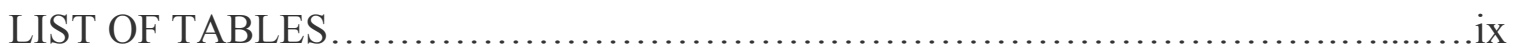

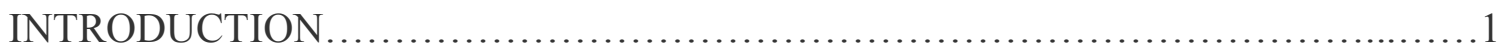

Importance of Executive Functioning in Early Childhood.......................2

Importance of Sleep in Early Childhood...................................4

Associations between Sleep and Executive Functioning.......................

Associations Between Family SES and Executive Functioning................9

SES as a Moderator of Associations Between Sleep and Executive Functioning.11

The Current Study.................................................. 12

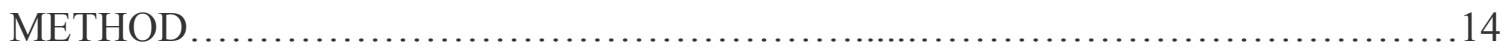

Participants....................................................... 14

Measures................................................................. 14

Procedure............................................................ 15

RESULTS................................................................ 17

Descriptives and Correlations.........................................17

Multiple Linear Regression Effects..................................... 18

Working Memory..........................................18 


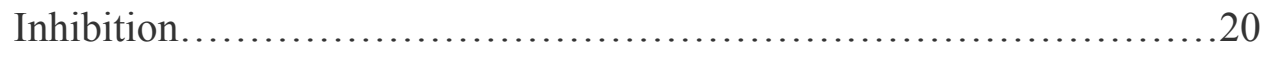

Exploratory Analyses................................................ 20

Sleep Length..............................................20

Minnesota Executive Functioning Scale (MEFS).....................21

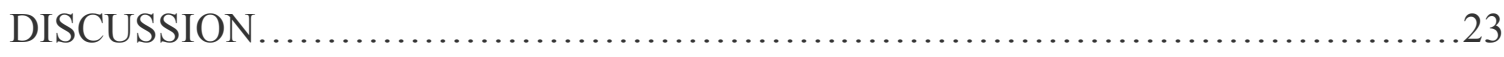

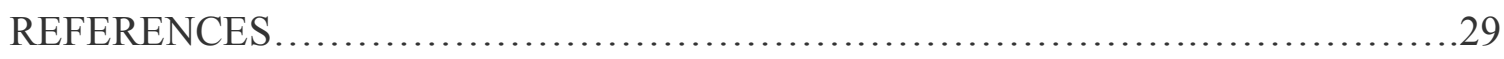

APPENDIX A: Childhood Executive Functioning Inventory (CHEXI) for Parents and

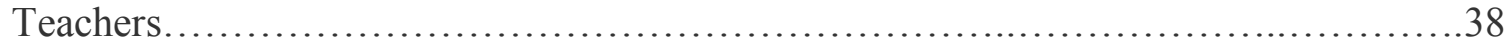

APPENDIX B: Tayside Children's Sleep Questionnaire...............................40 


\section{LIST OF FIGURES}

Figure 1: Mean problems in executive functioning for children in low, average, and high-income families when experiencing high and low sleep problems................19 


\section{LIST OF TABLES}

Table 1: Descriptive Statistics for Sleep Quality and EF......................................... 17

Table 2: Correlation Table................................................. 18

Table 3: Regression Analysis Summary for Parent Reports of Sleep Quality Problems Predicting Children's Problems with Working Memory.....................................19

Table 4: Regression Analysis Summary for Parent Reports of Sleep Quality Problems Predicting Children's Problems with Inhibition..........................20

Table 5: Regression Analysis Summary for Parent Reports of Sleep Quality Problems Predicting Assessed EF Skills in the Spring...............................22 


\section{INTRODUCTION}

In young children, sleep is essential to healthy development across all areas of performance (Zuckerman, Stevenson, \& Bailey, 1987; Thunström, 2002; Gregory \& O’Connor, 2002; Wong et al., 2004). Poor or inadequate sleep can impair social, emotional, and cognitive functioning in children due to its effects on the developing brain (Astill et al., 2012; Philbrook et al., 2017; Huntley \& Lewin, 2006; Sadeh et al., 2003; Steenari et al., 2003). Many children experience sleep difficulties, with one study (Bonuck et al., 2016) positing that $20 \%$ to $50 \%$ of children ages 3 to 5 experience sleeprelated issues. Another study found that the prevalence of "bedtime resistance" was $27 \%$ (Owens et al., 2000). This means that potentially a quarter to half of the nation's preschool-aged children are not getting the 10 to 13 hours of nightly sleep the National Sleep Foundation recommends (Hirschkowitz et al., 2015). Past research links children's sleep quality (defined by the National Sleep Foundation [2017] as: sleeping at least 85\% of the time spent in bed; falling asleep in 30 minutes or less; waking up no more than once per night; and being awake for 20 minutes or less after initially falling asleep) to their performance on tasks calling upon complex executive functioning (EF; Bernier et al., 2013) and suggests that children getting better quality sleep perform better in areas such as abstract reasoning, concept formation, and problem-solving. Additionally, studies have shown that children from low socioeconomic (SES) backgrounds are more 
vulnerable to poor sleep habits and are subsequently at risk for poorer cognitive performance (Philbrook et al., 2017).

There is a need for further research on this topic, as many studies have been done on adults and school age children, but very few investigations have delved into this subject in toddlers and preschool age children. This is a critical gap in the literature given that young children undergo a sensitive period in pre-frontal cortex development and associated EF in early childhood (Bell \& Wolfe, 2007; Anderson, Spencer-Smith, \& Wood, 2011; Sheridan \& Nelson, 2009) and also need more sleep than children in elementary school given this critical period in development (Bernier et al., 2013). Further, very few studies for any age group have examined whether better sleep habits are more closely linked to better EF for children from low-income homes specifically. The current study aims to fill in these gaps in the literature and evaluate socioeconomic status as a moderating variable in the association between children's and executive functioning such that children from low-SES homes will display better executive functioning skills when experiencing better quality of sleep Importance of Executive Functioning in Early Childhood

EF skills are cognitive skills linked to planning and problem solving. They include working memory, or the ability to hold information in mind and manipulate it, inhibitory control, or the ability to focus despite distractions, and attentional flexibility (Anderson, 2001). It has been noted that while executive function may be conceptualized as a single central control mechanism, it is also understood as involving multiple processing systems that are inter-related and inter-dependent, also interacting with factors operating outside it, including one's home and social environments (Anderson, 2002). 
EF is particularly important for healthy functioning because it can be linked to many long-term positive outcomes in varying areas. Given that young children undergo significant development in the pre-frontal cortex and subsequent executive functioning during this time and are more susceptible to damaging influences as a result, it is perhaps especially valuable to study the mechanisms underlying healthy development of executive functioning in this age group as opposed to others (Kalpakci, Ha, \& Sharpit 2018; Modi et al., 2017; Steward et al., 2017; Helder, Zuverza-Chavarria, \& Whitman, 2016). In early childhood, neural growth is particularly rapid, with the brain reaching $95 \%$ of its adult volume by age 6 . fMRI data indicate that there is significant movement from local functional connectivity to longer-range connectivity over childhood, while EEG studies reveal that EEG power and coherence during working memory tasks becomes centralized at the frontal cortex by age 4 (Bell \& Wolfe, 2007). This has noteworthy implications for development of the brain and the importance of external stimuli during this time frame.

It has long been asserted that brain development is not linear, but is characterized by a series of developmental spurts, often called critical or sensitive periods, in which the brain is particularly susceptible to both beneficial and harmful environmental influences which significantly affect subsequent developmental outcomes (Anderson, SpencerSmith, \& Wood, 2011). From 16 months to 2.5 years, dendrites display growth spurts leading to pruning, leaving only the most functional branches; this growth continues slowly until age 5 followed by a stable period for the next 27 years. The early experience hypothesis posits that the first 3 or so years of a child's life constitutes a relatively more important period in development because of the profound changes in the brain known to 
occur at that time (Sheridan \& Nelson, 2009). This means that developments made (or lack thereof) during this age range of 3 to 5 years are crucial to a child's lasting development.

One reason to examine this concept in early childhood is that individual differences in EF at young ages have been found to predict important developmental outcomes later in life. For example, in a follow-up study taken from work on delayed gratification, Mischel and colleagues assessed adolescents who as children had either refrained from taking a marshmallow in favor of a larger reward or had refused to wait and had eaten the marshmallow immediately. It was discovered that adolescents who had been patient were deemed by parents and peers as more interpersonally competent, and demonstrated better concentration, self-control, and frustration tolerance (Mischel, Shoda, \& Rodriguez, 1989; Shoda, Mischel, \& Peake, 1990).

A more recent longitudinal study found that self-control (similar to EF) measured between 3 and 11-year old children predicted physical health, substance dependence, SES, and the likelihood of a criminal conviction at age 32, even after controlling for social class of origin and IQ (Moffitt et al., 2011). Together, this evidence suggests not only the importance of understanding executive functioning as it relates to sensitive periods in childhood, but also accentuates the influence that executive functioning can have on meaningful consequences for people's lives.

\section{Importance of Sleep in Early Childhood}

Sleep is another factor which is extremely important in early childhood. It can be argued that sleep is the primary activity of the brain during these first years of life, as by age 2 the average child has spent 10,000 hours sleeping and roughly 7,500 hours in all 
waking activities combined (Dahl, 1996). From ages 2 to 5, an approximate even balance between sleep and wakefulness occurs. Therefore, it would seem that by the time a typical child enters preschool, they have spent more time asleep than in any interaction with family and peers. This suggests that early brain maturation depends on high amounts of sleep.

Additionally, the amount of sleep necessary for healthy functioning wanes as one ages. While the National Sleep Foundation recommends children ages 1-5 need between 10 and 14 hours of sleep, school-age children (ages 6-13) need 9-11 hours of sleep; this decreases even further into adolescence and young adulthood, (ages 14-25) where only 7 to 10 hours are needed, and 7-9 are recommended in middle and late adulthood (Hirschkowitz et al., 2015). This need for more sleep early in children's lives emphasizes its importance for healthy development.

A lack of sufficient sleep quality in infancy produces many negative outcomes in early childhood. A longitudinal study of 308 infants began when participants were 8 months old and 3 years of age found that those children with persistent sleep problems were more likely to exhibit behavioral issues, such as temper tantrums and behavior management issues (Zuckerman, Stevenson, \& Bailey, 1987). Thunström (2002) found further evidence to support this notion, as their findings revealed that one in four children with poor sleep quality in infancy qualified for the diagnosis of attention deficit hyperactivity disorder (ADHD) at age 5.5. While the sample size for this study was small, its conclusions point to the detrimental effects poor sleep quality can have on developing children. 
These effects not only impact children while they are still young but can also last through later years. Gregory \& O'Connor (2002) found that, in a longitudinal study examining problems with sleep quality in children beginning at age 4 and concluding at age 15 indicated that more sleep problems in early childhood predicted increases in depression/anxiety, inattention/overactivity, and aggression in mid-adolescence.

Additionally, they discovered a steady and significant increase in the overlap between sleep problems and depression/anxiety across the 11 years. Wong et al. (2004) found that sleep problems in early childhood (ages 3 to 5) served as a robust predictor for the use of substances such as alcohol, marijuana, cigarettes, and other drugs in adolescence (ages 12 to 14). Additionally, the consequences of poor sleep quality can have lasting effects into adulthood, as research has shown that persons (ages 21-30; $M=26$ ) with a lifetime history of sleep problems have higher rates of psychiatric disorders, especially major depression (Breslau et al., 1996). These and many other effects of poor sleep quality in infancy and early childhood emphasize the importance of the continuation and expansion of research on sleep in this age group.

While research exists on both the effects of sleep quality and sleep quantity on healthy development, prior literature seems to suggest that the former is especially important for long-term outcomes. In a longitudinal study spanning 8 years conducted by Clark and colleagues (2016) which examined the effects of impaired sleep duration and quality of sleep in adults on negative health outcomes (hypertension, diabetes, and dyslipidemia), it was discovered that shortened sleep length did not have a significant effect on these health problems. However, disruptions to sleep quality predicted subsequent risk of hypertension and dyslipidemia, both risk factors for cardiovascular 
disease. There is also evidence to suggest that poor sleep quality, rather than shorter sleep length, may be tied to the development of mental disorders in adolescence and early adulthood, namely anxiety and depression (Baglioni et al., 2011; Neckelmann, Mykletun, $\&$ Dahl, 2007). Because this research links reduced sleep quality, rather than sleep length, to poor, long-lasting health outcomes, the current study examined this facet of sleep in its primary analyses.

Associations between Sleep and Executive Functioning

In addition to other factors, sleep problems in both quality and quantity are linked with lower cognitive performance (Astill et al., 2012), and as sleep is essential in early childhood for healthy development, this presents an even greater risk to cognitive outcomes for children not getting adequate sleep. Philbrook and colleagues (2017) found that children who experienced longer and better sleep quality showed better cognitive performance and growth in such performance over time. Additionally, Huntley \& Lewin (2006) found that acute sleep restriction in children is associated with increased omission error on a neurocognitive task compared to baseline conditions taken two weeks prior. Prior research has also shown that school-aged children who experience lower sleep quality show significantly lower focused attention and higher error rates on visual and auditory memory tasks than children who sustain better sleeping habits (Sadeh et al., 2003; Steenari et al., 2003).

However, several studies have found that greater sleep quality, rather than sleep duration, was the more robust predictor of child cognitive outcomes in school-age children (ages 7 to 11; Staton et al., 2014; Gruber et al., 2014). However, other research has revealed that children getting higher proportions of sleep in infancy (age 1) tend to 
perform better on various tasks calling upon complex cognitive processes 3 years later (age 4; Bernier et al., 2013). Indeed, Astill and colleagues' (2012) meta-analysis revealed that "curtailment of sleep length but not sleep efficiency [quality] as associated with compromised executive functioning in children between the ages of 5 and 12" (pp. 1124). The discrepancies in these findings highlight the need for further research to be done in this area.

Longitudinal studies in later ages have recently been conducted to examine the long-term effects of poor sleep quality on cognitive performance. Buckhalt and colleagues (2009) have revealed that poor sleep quality in third grade negatively impacted academic performance two years later, in fifth grade. Bub et al. (2011) found similar results, discovering that disruptions to good sleep quality at age 8 predicted significant decreases in cognitive ability at age 11 . Another study assessed adolescents ages 13 to 14 for sleep-disordered breathing between ages two and six (Gozal \& Pope Jr., 2001). Results revealed that children who had experienced snoring and obstructed breathing during sleep in early childhood exhibited lower academic performance than their peers. These findings indicate that not only is adequate sleep in early age important, but it also has effects which can last across development.

In addition to executive functioning, other areas of cognitive performance have been researched with regard to sleep. Because it has been demonstrated that sleep affects higher order processing, Erath and colleagues (2014) proposed that fourth and fifth grade children (ages 8 to 10) with relatively low intelligence and poor sleep would experience lower levels of academic achievement than their intellectually matched peers with better 
sleep habits. Their results yielded evidence to support their theory and add to the body of literature asserting that lack of sleep affects cognition on a variety of levels.

While these studies outline the importance of sleep in early childhood, there is still a gap in the literature regarding sleep and its effects on the cognitive functioning in this population, especially as it relates to EF. Because we know less about these links as they pertain to this age group, the current study is especially important and seeks to illuminate the discrepancies and inconsistencies in the existing literature surrounding this subject.

Associations between Family SES and Executive Functioning

As the brain is undergoing rapid development and these skills are being honed in early childhood, it follows that one's environment is extremely important at that crucial stage. Adverse life experiences and childhood disadvantage at age 4 has been shown predict cognitive deficits at age 7 through the neurological effects of chronic stress (Berthelsen et al., 2017). Such toxic and long-term stress can diminish the brain's capacity to turn off elevated cortisol, causing impairments in mood-related functions and inhibiting neurogenesis, which is believed to play an important role in the encoding of memory (Shonkoff et al., 2012). This altered brain structure in response to toxic stress in early childhood could potentially explain the relationship between harmful situations in early childhood and issues in the development of linguistic, cognitive, and socialemotional skills.

Philbrook (2014) found that young children (age 9) of lower SES may be at greater risk for lower EF and a subsequent increase in stress, which may be exacerbated by difficulties associated with this poor economic standing. Previous research has 
exposed links between low SES and children's self-regulation and executive functioning abilities which may be accounted for by the increased stress levels associated with poverty (Blair, 2010). Perceived stress has been related to declines in working memory and deficits in set shifting, indicating that the stress children in low socioeconomic families may experience subsequent difficulties in various areas of executive functioning (Leuthi, Meier, \& Sandi, 2008; Orem, Petrac, \& Bedwell, 2008).

Research has shown there is also a potential for these effects to affect cognitive functioning into adolescence. A longitudinal study of children in Australia beginning at age 4 revealed that low socioeconomic position and higher child behavior risk (sleep problems, emotional dysregulation) negatively impacted cognitive control abilities in adolescence (age 15). With covariates entered, the relationship between family socioeconomic circumstances and executive function remained significant (Berthelsen et al., 2017). Samuels and colleagues (2016) examined disadvantaged children attending an urban, chartered middle/high school beginning in grade 6 and ending in grade 9 (ages 12 to 15$)$. This study revealed that poverty significantly and negatively affected children's EF, which directly predicted their GPAs across the 4-year time span. This suggests that not only do inadequate environments have a negative effect on executive function, but these effects can last years later.

Additionally, past research has shown that families with access to different types of capital are better equipped to provide an environment rich with activities to encourage optimal child development and cognitive stimulation (Rochette \& Bernier, 2014). These children have been shown to perform significantly better on both verbal and nonverbal tasks and show higher school achievement and IQ throughout childhood than their less 
privileged counterparts. Conversely, children in less resource-rich environments have limited access to these materials and may be at risk for developmental problems as a result. Children growing up in low SES environments also have higher potential for early physical growth retardation and inadequate neurobehavioral development as well as later sleep problems (Rochette \& Bernier, 2014). These issues can begin as early as infancy and continue into adulthood. Thus, the relationship between SES and executive functioning is robust as demonstrated by previous research.

\section{SES as a Moderator of Associations between Sleep and Executive Functioning}

While socioeconomic status and sleep have both been shown to be related to executive functioning, it can be seen that SES can play a moderating role in children's executive functioning, such that children in vulnerable and underserved families display EF skills more closely linked to their sleeping habits. Philbrook and colleagues (2014) found that 9-year old children, especially boys, from low SES homes were more susceptible to poorer cognitive outcomes at age 11 when getting less hours of sleep and poorer sleep quality than children in higher SES families. Staton (2014) also asserts the importance of sleep quality and quantity in protecting against the negative effects of SES on cognitive performance, discovering that when 9-year old children from low SES families obtained good sleep, they performed better on varied tasks examining executive functions and higher order processes.

Other studies have displayed similar results: SES serves as a moderator in the association between sleep duration, intellectual ability, and processing speed (Buckhalt et al., 2009). Furthermore, it has been shown that poor sleep and lower sleep quality were more strongly related to lower academic performance for children from lower SES 
backgrounds. Brown and Low (2008) found that children from disadvantaged and chaotic homes were at higher risk for sleep problems than those from more stable environments and were therefore more likely to display significantly worse academic performance. These results appear to suggest that the impact of poor sleep quality in cognitive performance in children of low SES is exacerbated relative to those of higher SES.

Buckhalt, El-Sheikh, and Keller (2007) found similar phenomena in that while 8 and 9-year old children from lower and higher SES executed cognitively-focused tasks, their performances were comparable, but when their sleep was disrupted, higher SES children displayed better cognitive functioning. They also found significant effects when incorporating race into their analyses. Whereas African American (AA) and European American (EA) children had similar scores when sleep was more optimal, AA children were at greater risk for lower cognitive performance. This suggests that both race and SES may contribute to executive functioning and a lack thereof when faced with poor sleep quality.

\section{The Current Study}

Through this literature analysis, it has been shown that both sleep quality (and in some cases quantity) and SES are closely tied to executive functioning in children. Further, previous studies have demonstrated SES to be a robust moderating variable in the relationship between sleep and executive functioning, such that good sleep quality is even more important for good cognitive functioning in children from low SES families. This evidence informs the current study and adds to its uniqueness in that it is only one of several studies in the literature which attempt to establish sleep as a protective factor for the EF of preschool-aged children from low SES homes. Based on this reviewed research 
and the conclusions reached, it was hypothesized that SES would moderate the association between children's sleep quality and their executive functioning such that children from low SES families would display better executive functioning skills when experiencing sufficient sleep quality. Given insufficient prior literature on whether sleep differentially impacts different executive functioning skills, differences among the two executive functioning skills measured (working memory and inhibitory control) were not hypothesized. 


\section{METHOD}

\section{Participants}

Data were drawn from an existing large-scale dataset collected to evaluate a preschool expansion project in the Midwest. The participants for the current study were 92 families participating in this preschool expansion project. Children were on average 56 months or 4 years, 8 months of age at the time of the study $(S D=3.7$ months $)$ and $60 \%$ were female. The average family income fell within the $\$ 25,000$ - $\$ 42,000$ range. Within the sample, $14.1 \%$ of families fell under the federal poverty line of $\$ 25,000$ for a family of four.

\section{Measures}

Two measures were utilized in the primary analyses, and two additional measures were introduced for exploratory analyses (which will be described in the results). The first is referred to as the Childhood Executive Function Inventory (CHEXI; Thorell \& Nyberg, 2008) and was utilized to measure executive functioning. The CHEXI is a 26item parent and teacher-rated scale which is divided into four subscales with the intent of evaluating a particular child's executive functioning: working memory (11 items), planning (4 items), inhibition (6 items), and regulation (5 items). Factor analyses have shown that utilizing two global scales within the measure yield results similar to those found when using all four subscales. These scales are working memory (total score of the working memory and planning subscales) and inhibition (total score of inhibition and 
regulation subscales). For the purposes of this study, the parent reports were analyzed. Test-retest reliability an average of 3 weeks after first completion of the survey was found to be adequate $(r=.89)$, with the inhibition scale yielding $.86 ; .84$ for the regulation subscale; .75 for the working memory subscale; and .94 for the planning subscale. In the current study, the mean scores from the two global scales (working memory and inhibition) were utilized, and in each case, higher scores indicated more executive functioning problems or difficulties.

The second is the Tayside children's sleep questionnaire (TCSQ; McGreavy et al., 2005) which was analyzed to identify problems in sleep quality and quantity as reported by their parents. This is a 10-item measure which assesses the child's sleep pattern over a three-month period. It is a Likert scale with scores ranging from 0 to 4 . The first item utilizes a 5-point intensity scale while the remainder use a 5-point frequency scale. The measure demonstrates good internal consistency, with Cronbach's alpha equaling 0.85 . The average of the sleep quality scale items 1 - 9 was used, where higher scores indicated more difficulties with sleep quality.

In addition to the measures aforementioned, the current study also utilized a demographics questionnaire to determine children's age, gender, and family socioeconomic status as measured using income brackets $(1=\$ 0-25,000 ; 2=\$ 25,001$ 42,$000 ; 3=\$ 42,001-\$ 60,000 ; 4=\$ 60,001-\$ 79,000 ; 5=\$ 79,000$-on).

\section{Procedure}

In the original evaluation from which data were drawn, parents provided their consent to participate in the early childhood expansion evaluation and were asked to provide their email if willing. A large battery of child, family, and classroom assessments 
were collected for this evaluation. The subset of questionnaires analyzed in the current study were collected using an online survey sent to parents' email addresses in the fall of their child's year of preschool entry. Online surveys were collected via a passwordprotected Survey Monkey account. For the current project, secondary data analysis was conducted to test the primary research question. 


\section{RESULTS}

\section{Descriptives and Correlations}

Ninety-two families consented to the online survey and provided information on their child's age in months, gender of child, family income, children's sleep habits, and children's executive functioning. See Table 1 for relevant descriptive statistics.

Table 1

Descriptive Statistics for Sleep Quality and EF

\begin{tabular}{lcccc}
\hline & Minimum & Maximum & $M$ & $S D$ \\
\hline TCSQ & 0.00 & 4.00 & 0.93 & 0.73 \\
CHEXI: Working Memory & 1.00 & 4.38 & 2.14 & 0.57 \\
CHEXI: Inhibition & 1.09 & 5.00 & 2.62 & 0.64 \\
\hline
\end{tabular}

Correlations were then computed between all variables (See Table 2). Neither age nor family income were significantly correlated with any variables. Gender was significantly associated with inhibition such that parents of boys reported that their child had more difficulties with inhibition, but no other variables. Sleep quality was significantly correlated with both working memory and inhibition such that when parents reported their children getting worse quality of sleep (higher TASQ scores), they had more difficulties with working memory and inhibition (higher CHEXI scores). Working memory and inhibition were also significantly positively associated with one another such that if a child had more difficulties with working memory, he/she also had more difficulties with inhibition. 
Table 2

Correlation Table

\begin{tabular}{lcccccc}
\hline Measure & 1. & 2. & 3. & 4. & 5. & 6. \\
\hline 1. Age in Months & - & & & & & \\
2. Gender & .081 & - & & & & \\
3. Family Income & .164 & .086 & - & & & \\
4. TCSQ & .034 & .171 & .032 & - & & \\
5. CHEXI: Working Memory & .203 & .185 & -.080 & $.212^{*}$ & - & \\
6. CHEXI: Inhibition & .121 & $.260^{*}$ & -.074 & $.307 * *$ & $.783^{* *}$ & - \\
\hline
\end{tabular}

*Correlation is significant at the 0.05 level (2-tailed)

**Correlation is significant at the 0.01 level (2-tailed)

Multiple Linear Regression Effects

Executive functioning scores, measured in the two domains of working memory and inhibition, were regressed onto sleep quality and family income and the interaction between sleep quality and income as well as covariates (age and gender). Measures were scored such that for both sleep quality and executive functioning, higher scores equal more difficulties or problems with the reported behavior. All variables were standardized before being entered into equations.

Working memory. Family income was not significantly associated with working memory, nor was sleep. However, these main effects were qualified by a significant interaction between sleep quality and family income (See Table 3 for relevant results). In order to further examine the significance and magnitude of the interaction of family income and sleep quality on working memory, the Preacher plotting tool for multiple linear regression was utilized (Preacher, Curran, \& Bauer, 2006; see Figure 1). Low, average, and high-income status was determined by plotting scores one standard deviation above and below the mean. These tests revealed that the slope for children from low-income backgrounds was significant such that children from low-income backgrounds showed significantly more working memory problems when they had 
greater instances of disruption to sleep quality, $B=0.448, S E=0.148, t(86)=3.020, p=$ .003. The slope for problems in working memory for children from backgrounds of average income when experiencing high and low sleep difficulties was not significant, $B$ $=0.138, S E=0.100, t(86)=1.38, p=.1709$, nor was that of children from high income families, $B=-.172, S E=-.173, t(86)=0.993, p=.323$.

Table 3

Regression Analysis Summary for Parent Reports of Sleep Quality Problems Predicting Children's Problems with Working Memory

\begin{tabular}{lccccc}
\hline Variable & $B$ & $S E B$ & $\beta$ & $t$ & $p$ \\
\hline Gender & 0.145 & 0.100 & 0.145 & 1.453 & .150 \\
Age in Months & 0.192 & 0.100 & 0.192 & 1.932 & .057 \\
Family Income & -0.153 & 0.100 & -0.153 & -1.538 & .128 \\
TCSQ-Quality & 0.138 & 0.101 & 0.138 & 1.368 & .175 \\
Income x TCSQ-Quality & -0.310 & 0.126 & -0.247 & -2.459 & .016 \\
\hline
\end{tabular}

Note. $R^{2}=.120(N=92, p=.009)$

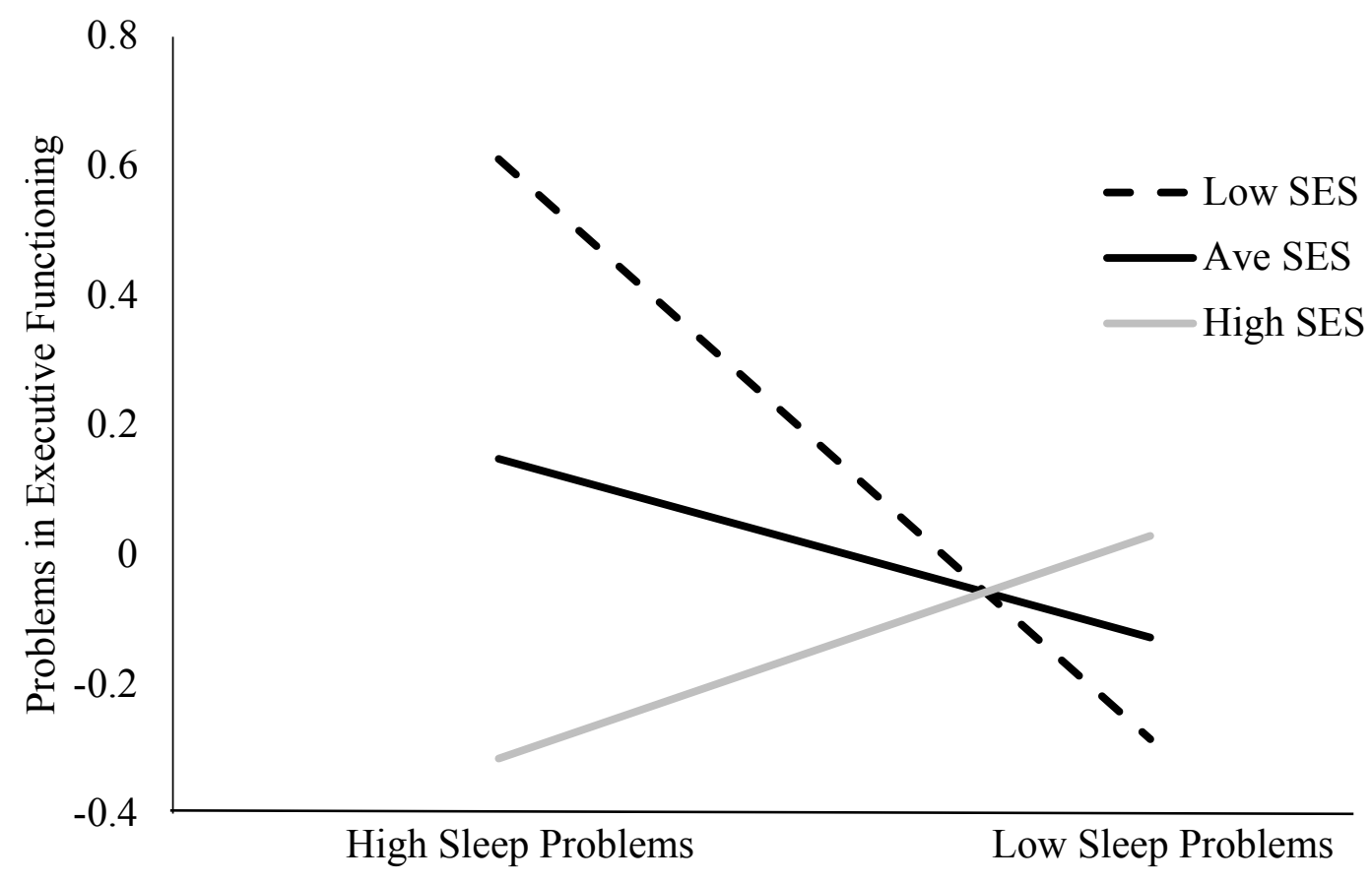

Figure 1. Mean problems in executive functioning for children in low (1 $S D$ below mean), average, and high-income ( $1 S D$ above mean) families when experiencing high and low sleep problems. 
Inhibition. Sleep quality was significantly associated with inhibition such that children who experienced fewer hindrances on their quality of sleep performed better on tasks evaluating inhibition. However, the association between family income and inhibition was not significant. The interaction between sleep quality and family income to predict inhibition was also not significant (See Table 4 for relevant results).

Table 4

Regression Analysis Summary for Parent Reports of Sleep Quality Problems Predicting Children's Problems with Inhibition

\begin{tabular}{lccccc}
\hline Variable & $B$ & $S E B$ & $\beta$ & $t$ & $p$ \\
\hline Gender & 0.214 & 0.100 & 0.005 & 0.048 & .961 \\
Age in Months & 0.107 & 0.100 & 0.107 & 1.069 & .035 \\
Family Income & -0.130 & 0.100 & -0.130 & -1.297 & .288 \\
TCSQ-Quality & 0.248 & 0.101 & 0.248 & 2.451 & .016 \\
Income x TCSQ-Quality & -0.148 & 0.126 & -0.118 & -1.175 & .243 \\
\hline
\end{tabular}

Note. $R^{2}=.117(N=92, p=.010)$

\section{Exploratory Analyses}

Sleep length. Exploratory analyses were then run to determine whether length of sleep could be a significant predictor of executive functioning because the literature is less clear on if the length of sleep might function similarly to sleep quality. The average sleep length of children was 10.45 hours $(S D=0.85)$. Sleep length was not correlated with sleep quality, $r=-0.185, p=.079$. Sleep length was not found to be significantly associated with working memory, $B=0.123, S E=0.109, t(85)=1.137, p=.259$, nor was the interaction of family income and sleep length, $B=-0.053, S E=0.126, t(85)=-0.419$, $p=.259$. Sleep length was also not significantly associated with inhibition, $B=0.115, S E$ $=0.110, t(85)=1.048, p=.298$, nor was the interaction of family income and sleep length, $B=0.105, S E=0.128, t(85)=0.824, p=0.412$. 
Minnesota Executive Functioning Scale (MEFS). The data set used in the current study contained direct assessments of EF for a sub-sample of the children $(n=41)$ via the Minnesota Executive Function Scale (MEFS; Carlson \& Zelazo, 2014), a standardized assessment of EF skills designed for children ages 2 and above and which is administered on an iPad or Android touch-screen tablet. Exploratory analyses were conducted using this data to determine if the same pattern of associations found using the CHEXI would also be found with this measure. These data were collected in the fall at the onset of the school year, and again in the spring for follow-up scores. Spring MEFS scores were regressed on our predictors of interest as well as fall MEFS scores.

For spring MEFS scores, family income was significantly associated with outcomes such that higher family income predicted better performance on the MEFS (See Table 5). Fall MEFS scores were also associated with spring scores, such that better performance during the fall assessment predicted better EF skills in the spring. Additionally, spring MEFS scores were significantly correlated with CHEXI scores related to working memory such that higher scores on the spring MEFS were associated with fewer problems with working memory, $r=-0.345, p=.027$. Spring MEFS scores were not associated with inhibition, $r=-0.272, p=.085$. Neither sleep quality nor the interaction of family income and sleep quality were significantly associated with spring MEFS scores. However, the effects of both family income and sleep quality on spring MEFS scores in both cases were of substantial magnitude and were the strongest predictors of spring EF skills after fall EF skills. Detection of significant effects may have been limited by the small sample size for this exploratory analysis. Sleep length was not significantly associated with spring MEFS scores, $B=-0.100, S E=0.162, t(38)=$ - 
$0.615, p=.542$, nor was the interaction of sleep length and family income, $B=0.079, S E$ $=0.153, t(38)=1.804, p=.609$.

Table 5

Regression Analysis Summary for Parent Reports of Sleep Quality Problems Predicting Assessed EF Skills in the Spring

\begin{tabular}{lccccc}
\hline Variable & $B$ & $S E B$ & $\beta$ & $t$ & $p$ \\
\hline Gender & 0.080 & 0.136 & 0.084 & 0.590 & .559 \\
Age in Months & 0.075 & 0.137 & 0.085 & 0.546 & .589 \\
Family Income & 0.275 & 0.152 & 0.339 & 1.813 & .079 \\
TCSQ-Quality & -0.308 & 0.170 & -0.260 & -1.816 & .079 \\
Income x TCSQ-Quality & 0.143 & 0.187 & 0.116 & 0.760 & .453 \\
Fall MEFS & 0.331 & 0.148 & 0.405 & 2.233 & .033 \\
\hline
\end{tabular}

Note. $R^{2}=.294(N=39, p=.009)$ 


\section{DISCUSSION}

The purpose of the current study was to determine the associations between sleep quality and executive functioning among children from low and high-income backgrounds. It was hypothesized that socioeconomic status would moderate the relationship between sleep habits and executive functioning, such that children from low income families would display better executive functioning skills when getting adequate sleep quality. This hypothesis was supported for working memory in that children from low-income homes displayed fewer executive functioning difficulties when experiencing less disrupted sleep quality. Higher sleep quality was associated with better inhibition scores overall, but the interaction between sleep quality and family income was not a significant predictor of inhibition.

The findings of the current study are consistent with those with older children finding some evidence for a moderating role of SES in the association between sleep quality and working memory (e.g., Buckhalt, El-Sheikh, \& Keller, 2007; Staton et al., 2014). The current study extends these results by showing similar patterns with younger children. Indeed, developmental sleep theory suggests that the negative effects of poor sleep quality should be apparent in tasks with substantial cognitive load, particularly those which assess abilities settled in the prefrontal cortex (Dahl, 1996; Sadeh, 2007). Children from low-SES backgrounds are more susceptible to the loss of sleep, potentially influenced by lack of family resources, chaotic homes, and a number of other factors 
(Philbrook et al., 2014; Staton at al., 2014; Buckhalt et al., 2009; Buckhalt, El-Sheikh, \& Keller, 2007; Brown \& Low, 2008). Therefore, getting better quality sleep may be particularly important for young children who live in poverty.

The research on inhibitory control as it relates to sleep quality is less extensive than that of working memory and has somewhat more mixed findings. Some report that sleep quality predicted better performance on tasks of inhibition in children ages 7 to 11 when utilizing teacher-reports of behavior (Gruber, Cassoff, Frenette, Wiebe, \& Carrier, 2012), while other studies of children ages 8 to 15 have found null effects and others still have found than an increase in poor sleep quality may actually be linked to positive outcomes in inhibitory control when measuring sleep using actigraphy and researcherassessed neurobehavioral functioning (Fallone, Acebo, Arnedt, Seifer, \& Carskadon, 2001; Sadeh, Gruber, \& Raviv, 2003). This may be due to a certain level of "hypoactivity," an effect of poor sleep quality, which may then delay responses and slow cognitive tempo otherwise heightened by hyperactivity of impulsivity (Fallone, Acebo, Seifer, \& Carskadon, 2005).

Prior research has often been limited in examining working memory and inhibition in isolation rather than measuring both within the same sample. This unique aspect of this study provides insights into how findings compare across the working memory and inhibitory control. Several factors linked to low-SES status have been found to be more strongly associated to working memory than inhibition, which could help explain the results from the current study. For example, Leuthi et al (2009) found that stress had significant and damaging effects on participants' working memory, particularly when exposed to the prolonged stresses of poverty (Shonkoff et al., 2012). Such effects 
were not found when examining stress and its relationship to inhibition. Other studies have found that SES has a stronger effect on children's visuospatial working memory tasks than on those calling on response inhibition (Corso et al., 2016). Therefore, it could be that young children's working memory is more susceptible to the environmental influences associated with low-SES status, including the increased likelihood of poor sleep quality.

The exploratory analyses examining the associations between sleep quantity, income, and EF were not significant, suggesting that sleep duration and sleep quality do not relate similarly to children's EF skills. This finding is supported by previous literature, which found that sleep length was not as important a determinant for cognitive functioning as sleep quality (Gruber at al., 2014). Staton and colleagues (2014) found similar results in their study of sleep and cognitive performance in children with respiratory and sinus arrhythmia activity. These results, combined with those from the current study, suggest that sleep quality rather than quantity, is more closely related to children's cognitive outcomes.

The additional exploratory analyses utilizing the MEFS as an assessment of childhood EF were not significant. This could be due to the small proportion of children in the study who had completed both the fall and spring MEFS assessments. The MEFS has been found to be a reliable predictor of children's EF skills and has been utilized in several populations to add to its utility (Carlson \& Zelazo, 2014). However, prior literature suggests that direct assessments of EF and parent and teacher reports of EF may be measuring different aspects of this construct. Fuhs and colleagues (2015) found that, when examining academic achievement in preschool-age children, teacher reports are 
more significantly associated with literacy and language. These may be more strongly affected by how children use their EF skills in the classroom, as opposed to direct assessments of EF, which were more strongly related to mathematics and demonstrate the underlying cognitive processes themselves. This suggests that direct assessments of EF may capture children's available cognitive processes while teacher-, and in this study, parent-reports may assess how these skills are utilized in a real-world setting and may explain why the current study did not find the same effects of sleep quality and income across different measures of EF. Future research using a larger sample size will be important to better test these associations using a multi-method battery of EF assessments.

Due to the distractibility and hyperactivity some children experience, bedtime resistance may also be fairly common (Yürümez \& K1lıç, 2016). Therefore, sleep training has the potential be more difficult and subsequent sleeping problems may be more likely to occur. Such difficulties with sleep can then contribute negatively to the mastery of tasks involving working memory when executed by children with attentional problems and hyperactivity (Sciberras et al., 2015). In this way, sleep problems and executive functioning may relate to one another bidirectionally, but few studies examine these constructs in this way. While Mulraney and colleagues (2016) sought to investigate this relationship by studying the sleeping problems and internalizing and externalizing problems of children (ages 5-13) who had attentional difficulties, their results yielded a weak association with the two at baseline, but no evidence of a longitudinal relationship. Future research should consider these factors, examining EF and sleep from both sides in 
order to better inform our understanding of the causal relationship of sleep and difficulties in EF for preschool-age children.

The current study was strengthened by the diversity of the sample of children and their families. Family income was captured at a variety of levels in utilizing a sample which represented both affluent and impoverished families. Additionally, children's ages were varied, allowing for a broader interpretation of children's EF skills across ages which may vary significantly given the rapid cognitive development which takes place in early childhood. However, the sample was smaller than what would have been ideal with respect to the exploratory analyses using the MEFS, allowing for more precise depictions of the relationship between family income, sleep problems and assessed EF to be captured. Measuring sleep habits using parent reports as opposed to more sophisticated methods (actigraphy, polysomnography) may not capture its complexities or distinguish between rapid eye movement (REM) and non-rapid eye movement (NREM) sleep, which both have their own unique contributions to sleep quality. Additionally, parent reports of EF may be influenced by outside factors. Because parents, especially those with preschool-age children, tend to evaluate their child's cognitive and academic success based on how well the child follows school rules and gets along with teachers and other students, their depictions of children's EF may not be entirely accurate (Owens et al., 2015). However, the current study found spring MEFS scores to be significantly correlated with CHEXI scores, suggesting that the direct assessments and parent-reports may overlap in their measurement of children's EF. A final limitation is that the data for the current study (excluding the MEFS assessments utilized in the exploratory analyses) were also collected at a single time point; therefore, it is not possible to determine the 
direction of effect between predictor and outcome variables or any changes in associations over time.

In conclusion, the current findings suggest that there are significant associations between sleep quality and children's working memory and inhibitory control and that the effects for working memory were more pronounced for children from low-income homes. As preschool age children go through rapid brain development of the prefrontal cortex where EF skills are advanced, and given the long-term outcomes associated with sleep problems during this age, it becomes increasingly important to understand the mechanisms by which their sleep habits and grasp of crucial EF skills are affected. By having a better knowledge of what impacts sleep habits and subsequent EF most significantly in early childhood, as well as understanding the value of early identification and treatment of sleep problems in this population, programs can be implemented by schools and families to protect against these negative effects and support children's academic and social growth. 


\section{REFERENCES}

Anderson, V. (1998). Assessing executive functions in children: Biological, psychological, and developmental considerations. Neuropsychological Rehabilitation, 8(3), 319-349. doi:10.1080/713755568

Anderson, P. (2002). Assessment and development of executive function (EF) during childhood. Child neuropsychology, 8(2), 71-82.

Anderson, V., Spencer-Smith, M., \& Wood, A. (2011). Do children really recover better? Neurobehavioural plasticity after early brain insult. Brain: A Journal Of Neurology, 134(8), 2197-2221. doi:10.1093/brain/awr103

Astill, R. G., Van der Heijden, K. B., Van IJzendoorn, M. H., \& Van Someren, E. J. (2012). Sleep, cognition, and behavioral problems in school-age children: A century of research meta-analyzed. Psychological bulletin, 138(6), 1109.

Baglioni, C., Battagliese, G., Feige, B., Spiegelhalder, K., Nissen, C., Voderholzer, U., ... Riemann, D. (2011). Insomnia as a predictor of depression: a meta-analytic evaluation of longitudinal epidemiological studies. Journal of affective disorders, 135(1), 10-19.

Bernier, A., Beauchamp, M. H., Bouvette-Turcot, A., Carlson, S. M., \& Carrier, J. (2013). Sleep and cognition in preschool years: specific links to executive functioning. Child Development, 84(5), 1542-1553. doi:10.1111/cdev.12063

Berthelsen, B.., Hayes, N., White, S. L. J., W., \& Williams, K. E. (2017). Executive 
function in adolescence: associations with child and family risk factors and selfregulation in early childhood. Frontiers In Psychology, 8, 903.

Blair, C. (2010). Stress and the development of self-regulation in context. Child Dev Perspectives, 4, 181-188.

Bonuck, K. A., Blank, A., True-Felt, B., \& Chervin, R. (2016). Promoting sleep health among families of young children in head start: protocol for a social-ecological approach. Preventing Chronic Disease, 13, 1-8. doi:10.5888/pcd13.160144

Breslau, N., Roth, T., Rosenthal, L., \& Andreski, P. (1996). Sleep disturbance and psychiatric disorders: a longitudinal epidemiological study of young adults. Biological Psychiatry, 39(6), 411-418.

Brown, E. D., \& Low, C. M. (2008). Chaotic living conditions and sleep problems associated with children's responses to academic challenge. Journal of Family Psychology, 22(6), 920.

Buckhalt, J. A., El-Sheikh, M., \& Keller, P. (2007). Children's sleep and cognitive functioning: race and socioeconomic status as moderators of effects. Child Development, 78(1), 213-231. doi:10.1111/j.1467-8624.2007.00993.x

Buckhalt, J. A., El-Sheikh, M., Keller, P. S., \& Kelly, R. J. (2009). Concurrent and longitudinal relations between children's sleep and cognitive functioning: The moderating role of parent education. Child Development, 80(3), 875-892.

Carlson, S. M., \& Zelazo, P. D. (2014). Minnesota executive function scale. Test manual. Reflection Sciences, LLC: St. Paul, MN.

Chervin, R. D., Dillon, J. E., Bassetti, C., Ganoczy, D. A., Pituch, K. J. (1997). Pediatrics and sleep symptoms of sleep disorders, inattention, and hyperactivity in children. 
Sleep, 20, 1185-1192.

Clark, A. J., Salo, P., Lange, T., Jennum, P., Virtanen, M., Pentti, J., ... Vahtera, J. (2016). Onset of impaired sleep and cardiovascular disease risk factors: A longitudinal study. Sleep, 39(9), 1709-1718.

Clark, C. C., Chevalier, N., Nelson, J. M., James, T. D., Garza, J. P., Choi, H., \& Espy, K. A. (2016). The changing nature of executive control in preschool: I. Executive control in early childhood. Monographs Of The Society For Research In Child Development, 81(4), 7-29. doi:10.1111/mono.12268

Corkum, P., Moldofsky, H., Hogg-Johnson, S., Humphries, T., \& Tannock, R. (1999). Sleep problems in children with attention-deficit hyperactivity disorder: Impact of subtype, comorbidity, and stimulant medication. Journal of the American Academy of Child \& Adolescent Psychiatry, 38, 1285-1293.

Corso, H. V., Cromley, J. G., Sperb, T., \& Salles, J. F. (2016). Modeling the relationship among reading comprehension, intelligence, socioeconomic status, and neuropsychological functions: The mediating role of executive functions. Psychology \& Neuroscience, 9(1), 32-45. doi:10.1037/pne0000036

Cortese, S., Konofal, E., Lecendreux, M., Arnulf, I., Mouren, M. C., Darra, F., \& Dalla Bernardina, B. (2005). Restless legs syndrome and attention-deficit/hyperactivity disorder: A review of the literature. Sleep, 8, 1007-1013.

Dahl, R. E. (1996). The impact of inadequate sleep on children's daytime cognitive function. Seminars in Pediatric Neurology, 3(1), 44-50. WB Saunders.

El-Sheikh, M., Tu, K. M., Erath, S. A., \& Buckhalt, J. A. (2014). Family stress and adolescents' cognitive functioning: Sleep as a protective factor. Journal Of 
Family Psychology, 28(6), 887-896. doi:10.1037/fam0000031

Erath, S. A., Tu, K. M., Buckhalt, J. A., \& El-Sheikh, M. (2015). Associations between children's intelligence and academic achievement: The role of sleep. Journal Of Sleep Research, 24(5), 510-513. doi:10.1111/jsr.12281

Fallone, G., Acebo, C., Arnedt, J. T., Seifer, R., \& Carskadon, M. A. (2001). Effects of acute sleep restriction on behavior, sustained attention, and response inhibition in children. Perceptual and Motor Skills, 93(1), 213-229.

Fuhs, M. W., Farran, D. C., \& Nesbitt, K. T. (2015). Prekindergarten children's executive functioning skills and achievement gains: The utility of direct assessments and teacher ratings. Journal Of Educational Psychology, 107(1), 207-221. doi:10.1037/a0037366

Gruber, R., Cassoff, J., Frenette, S., Wiebe, S., \& Carrier, J. (2012). Impact of sleep extension and restriction on children's emotional lability and impulsivity. Pediatrics, 130(5), e1155-e1161.

Gruber, R., Somerville, G., Enros, P., Paquin, S., Kestler, M., \& Gillies-Poitras, E. (2014). Sleep efficiency (but not sleep duration) of healthy school-age children is associated with grades in math and languages. Sleep Medicine, 15(12), 15171525.

Harvey, A. G., Mullin, B. C., \& Hinshaw, S. P. (2006). Sleep and circadian rhythms in children and adolescents with bipolar disorder. Development and Psychopathology, 18(4), 1147-1168.

Hirshkowitz, M., Whiton, K., Albert, S. M., Alessi, C., Bruni, O., DonCarlos, L., ... Kheirandish-Gozal, L. (2015). National Sleep Foundation's updated sleep 
duration recommendations. Sleep Health: Journal of the National Sleep Foundation, 1(4), 233-243.

Hiscock, H., Canterford, L., Ukoumunne, O. C., \& Wake, M. (2007). Adverse associations of sleep problems in Australian preschoolers: National Population Study. Pediatrics, 119, 86-93.

Huntley, E., \& Lewis, D. S. (2006). The effects of sleep restriction on performance testing on children with obstructive sleep apnea (OSA) and a healthy comparison guide. Submitted for the Associated Professional Sleep Societies 2006 annual meeting.

Kalpakci, A., Ha, C., \& Sharp, C. (2018). Differential relations of executive functioning to borderline personality disorder presentations in adolescents. Personality And Mental Health, 12(2), 93-106.

Luethi, M., Meier, B., \& Sandi, C. (2009). Stress effects on working memory, explicit memory, and implicit memory for neutral and emotional stimuli in healthy men. Frontiers in Behavioral Neuroscience, 2, 5.

McGreavey, J. A., Donnan, P. T., Pagliari, H. C., \& Sullivan, F. M. (2005). The Tayside children's sleep questionnaire: A simple tool to evaluate sleep problems in young children. Child: Care, Health And Development, 31(5), 539-544. doi:10.1111/j.1365-2214.2005.00548.x

Mischel, W., Shoda, Y., \& Rodriguez, M. I. (1989). Delay of gratification in children. Science, 244(4907), 933-938.

Modi, A. C., Schmidt, M., Smith, A. W., Turnier, L., Glaser, N., \& Wade, S. L. (2017). Development of a web-based executive functioning intervention for adolescents 
with epilepsy: The Epilepsy Journey. Epilepsy \& Behavior, 72114-121.

doi:10.1016/j.yebeh.2017.04.009

Moffitt, T. E., Arseneault, L., Belsky, D., Dickson, N., Hancox, R. J., Harrington, H., ... Sears, M. R. (2011). A gradient of childhood self-control predicts health, wealth, and public safety. Proceedings of the National Academy of Sciences, 108(7), 2693-2698.

Neckelmann, D., Mykletun, A., \& Dahl, A. A. (2007). Chronic insomnia as a risk factor for developing anxiety and depression. Sleep, 30(7), 873-880.

National Sleep Foundation (2017). What is good quality sleep? Retrieved June 15, 2018, from https://sleepfoundation.org/press-release/what-good-quality-sleep

Orem, D. M. Petrac, D. C., \& Bedwell, J. S. (2008). Chronic self-perceived stress and setshifting performance in undergraduate students. Stress, 11(1), 73-78.

Owens, J. A., Spirito, A., McGuinn, M., \& Nobile, C. (2000). Sleep habits and sleep disturbance in elementary school-aged children. Journal Of Developmental And Behavioral Pediatrics, 21(1), 27-36. doi:10.1097/00004703-200002000-00004

Owens, J. S., Storer, J., Holdaway, A. S., Serrano, V. J., Watabe, Y., Himawan, L. K., \& ... Andrews, N. (2015). Screening for social, emotional, and behavioral problems at kindergarten entry: Utility and incremental validity of parent report. School Psychology Review, 44(1), 21-40. doi:10.17105/SPR44-1.21-40

Philbrook, L. E., Hinnant, J. B., Elmore-Staton, L., Buckhalt, J. A., \& El-Sheikh, M. e. (2017). Sleep and cognitive functioning in childhood: ethnicity, socioeconomic status, and sex as moderators. Developmental Psychology, 53(7), 1276-1285.

Preacher, K. J., Curran, P. J., \& Bauer, D. J. (2006). Computational tools for probing 
interaction effects in multiple linear regression, multilevel modeling, and latent curve analysis. Journal of Educational and Behavioral Statistics, 31, 437-448.

Rochette, É., \& Bernier, A. (2014). Parenting, family socioeconomic status, and child executive functioning: A longitudinal study. Merrill-Palmer Quarterly, 60(4), 431-460. doi:10.13110/merrpalmquar1982.60.4.0431

Sadeh, A. (2007). Consequences of sleep loss or sleep disruption in children. Sleep Medicine Clinics, 2(3), 513-520.

Sadeh, A., Gruber, R., \& Raviv, A. (2003). The effects of sleep restriction and extension on school-age children: What a difference an hour makes. Child Development, 74(2), 444-455.

Samuels, W. E., Tournaki, N., Blackman, S., \& Zilinski, C. (2016). Executive functioning predicts academic achievement in middle school: A four-year longitudinal study. The Journal of Educational Research, 109(5), 478-490. doi:10.1080/00220671.2014.979913

Sciberras, E., DePetro, A., Mensah, F., \& Hiscock, H. (2015). Association between sleep and working memory in children with ADHD: A cross-sectional study. Sleep Medicine, 16(10), 1192-1197. doi:10.1016/j.sleep.2015.06.006

Sheridan, M., \& Nelson, C. A. (2009). Neurobiology of fetal and infant development. Handbook of Infant Mental Health, 3, 40-58.

Shoda, Y., Mischel, W., \& Peake, P. K. (1990). Predicting adolescent cognitive and selfregulatory competencies from preschool delay of gratification: Identifying diagnostic conditions. Developmental Psychology, 26(6), 978.

Shonkoff, J. P., Garner, A. S., Siegel, B. S., Dobbins, M. I., Earls, M. F., McGuinn, L., ... 
\& Committee on Early Childhood, Adoption, and Dependent Care. (2012). The lifelong effects of early childhood adversity and toxic stress. Pediatrics, 129(1), e232-e246.

Shumow, L., Vandell, D. L., \& Posner, J. K. (1998). Harsh, firm, and permissive parenting in low-income families: Relations to children's academic achievement and behavioral adjustment. Journal Of Family Issues, 19(5), 483-507. doi:10.1177/019251398019005001

Staton, L., Hinnant, J. B., Buckhalt, J., \& El-Sheikh, M. (2014). Sleep and cognitive performance: The role of income and respiratory sinus arrhythmia reactivity. Developmental Psychobiology, 56(7), 1528-1540. doi:10.1002/dev.21247

Steenari, M. R., Vuontela, V., Paavonen, E. J., Carlson, S., Fjällberg, M., \& Aronen, E. T. (2003). Working memory and sleep in 6-to 13-year-old schoolchildren. Journal of the American Academy of Child \& Adolescent Psychiatry, 42(1), 85-92.

Steward, K. A., Tan, A., Delgaty, L., Gonzales, M. M., \& Bunner, M. (2017). Selfawareness of executive functioning deficits in adolescents with ADHD. Journal Of Attention Disorders, 21(4), 316-322. doi:10.1177/1087054714530782

Thorell, L. B., \& Nyberg, L. (2008). The Childhood Executive Functioning Inventory (CHEXI): A new rating instrument for parents and teachers. Developmental Neuropsychology, 33(4), 536-552. doi:10.1080/87565640802101516

Touchette, É., Petit, D., Séguin, J. R., Boivin, M., Tremblay, R. E., \& Montplaisir, J. Y. (2007). Associations between sleep duration patterns and behavioral/cognitive functioning at school entry. Sleep, 30(9), 1213-1219. 
Van der Heijden, K. B., Smits, M. G., Van Someren, E. J. W., \& Gunning, W. B. (2005). Idiopathic chronic sleep onset insomnia in attention-deficit/hyperactivity disorder: A circadian rhythm sleep disorder. Chronobiology International, 22, 559-570.

Vriend, J. L., Davidson, F. D., Corkum, P. V., Rusak, B., Chambers, C. T., \& McLaughlin, E. N. (2013). Manipulating sleep duration alters emotional functioning and cognitive performance in children. Journal of Pediatric Psychology, 38(10), 1058-1069.

Vriend, J., Davidson, F., Rusak, B., \& Corkum, P. (2015). Emotional and cognitive impact of sleep restriction in children. Sleep Medicine Clinics, 10(2), 107-115.

Wolfe, C. D., \& Bell, M. A. (2007). The integration of cognition and emotion during infancy and early childhood: Regulatory processes associated with the development of working memory. Brain and Cognition, 65(1), 3-13.

Wong, M. M., Brower, K. J., Fitzgerald, H. E., \& Zucker, R. A. (2004). Sleep problems in early childhood and early onset of alcohol and other drug use in adolescence. Alcoholism: Clinical and Experimental Research, 28(4), 578-587.

Zelazo, P. D., \& Carlson, S. M. (2012). Hot and cool executive function in childhood and adolescence: Development and plasticity. Child Development Perspectives, 6(4), 354-360. doi:10.1111/j.1750-8606.2012.00246.x

Zuckerman, B., Stevenson, J., \& Bailey, V. (1987). Sleep problems in early childhood: Continuities, predictive factors, and behavioral correlates. Pediatrics, 80(5), 664671. 


\section{APPENDIX A}

Childhood Executive Functioning Inventory (CHEXI) for Parents and Teachers

Below, you will find a number of statements. Please read each statement carefully and thereafter indicate how well that statement is true for the child. You indicate your response by circling one of the numbers (from 1 to 5) after each statement.

\begin{tabular}{|c|c|c|c|c|}
\hline Definitely not true & Not true & Partially true & True & Definitely true \\
1 & 2 & 3 & 4 & 5 \\
\hline
\end{tabular}

\begin{tabular}{|l|c|c|c|c|c|}
\hline 1. Has difficulty remembering lengthy instructions & 1 & 2 & 3 & 4 & 5 \\
\hline $\begin{array}{l}\text { 2. Seldom seems to be able to motivate him/herself to } \\
\text { do something that he/she doesn't want to do }\end{array}$ & 1 & 2 & 3 & 4 & 5 \\
\hline $\begin{array}{l}\text { 3. Has difficulty remembering what he/she is doing in } \\
\text { the middle of an activity }\end{array}$ & 1 & 2 & 3 & 4 & 5 \\
\hline $\begin{array}{l}\text { 4. Has difficulty following through on less appealing } \\
\text { tasks unless he/she is promised some type of reward for } \\
\text { doing so }\end{array}$ & 1 & 2 & 3 & 4 & 5 \\
\hline $\begin{array}{l}\text { 5. Has a tendency to do things without first thinking } \\
\text { about what could happen }\end{array}$ & 1 & 2 & 3 & 4 & 5 \\
\hline $\begin{array}{l}\text { 6. When asked to do several things, he/she only } \\
\text { remembers the first or last }\end{array}$ & 1 & 2 & 3 & 4 & 5 \\
\hline $\begin{array}{l}\text { 7. Has difficulty coming up with a different way of } \\
\text { solving a problem when he/she gets stuck }\end{array}$ & 1 & 2 & 3 & 4 & 5 \\
\hline $\begin{array}{l}\text { 8. When something needs to be done, he/she is often } \\
\text { distracted by something more appealing }\end{array}$ & 1 & 2 & 3 & 4 & 5 \\
\hline 9. Easily forgets what he/she is asked to fetch & 1 & 2 & 3 & 4 & 5 \\
\hline $\begin{array}{l}\text { 10. Gets overly excited when something special is going } \\
\text { to happen (e.g., going on a field trip, going to a party }\end{array}$ & 1 & 2 & 3 & 4 & 5 \\
\hline $\begin{array}{l}\text { 11. Has clear difficulties doing things he/she finds } \\
\text { boring }\end{array}$ & 1 & 2 & 3 & 4 & 5 \\
\hline $\begin{array}{l}\text { 12. Has difficulty planning for an activity (e.g., } \\
\text { remembering to bring everything necessary for a field } \\
\text { trip or things needed for school) }\end{array}$ & 1 & 2 & 3 & 4 & 5 \\
\hline
\end{tabular}




\begin{tabular}{|l|l|l|l|l|c|}
\hline $\begin{array}{l}\text { 13. Has difficulty holding back his/her activity despite } \\
\text { being told to do so }\end{array}$ & 1 & 2 & 3 & 4 & 5 \\
\hline $\begin{array}{l}\text { 14. Has difficulty carrying out activities that require } \\
\text { several steps (e.g., for younger children, getting } \\
\text { completely dressed without reminders; for older } \\
\text { children, doing all homework independently) }\end{array}$ & 1 & 2 & 3 & 4 & 5 \\
\hline $\begin{array}{l}\text { 15. In order to be able to concentrate, he/she must find } \\
\text { the task appealing }\end{array}$ & 1 & 2 & 3 & 4 & 5 \\
\hline $\begin{array}{l}\text { 16. Has difficulty refraining from smiling or laughing in } \\
\text { situations where it is inappropriate }\end{array}$ & 1 & 2 & 3 & 4 & 5 \\
\hline $\begin{array}{l}\text { 17. Has difficulty telling a story about something that } \\
\text { has happened so that others may easily understand }\end{array}$ & 1 & 2 & 3 & 4 & 5 \\
\hline $\begin{array}{l}\text { 18. Has difficulty stopping an activity immediately upon } \\
\text { being told to do so. For example, he/she needs to jump a } \\
\text { couple of extra times or play on the computer a little bit } \\
\text { longer after being asked to stop }\end{array}$ & 1 & 2 & 3 & 4 & 5 \\
\hline $\begin{array}{l}\text { 19. Has difficulty understanding verbal instructions } \\
\text { unless he/she is also shown how to do something }\end{array}$ & 1 & 2 & 3 & 4 & 5 \\
\hline $\begin{array}{l}\text { 20. Has difficulty with tasks or activities that involve } \\
\text { several steps }\end{array}$ & 1 & 2 & 3 & 4 & 5 \\
\hline $\begin{array}{l}\text { 21. Has difficulty thinking ahead or learning from } \\
\text { experience }\end{array}$ & 1 & 2 & 3 & 4 & 5 \\
\hline $\begin{array}{l}\text { 22. Acts in a wilder way compared to other children in a } \\
\text { group (e.g., at a birthday party or during a group activity }\end{array}$ & 1 & 2 & 3 & 4 & 5 \\
\hline $\begin{array}{l}\text { 23. Has difficulty doing things that require mental } \\
\text { effort, such as counting backwards }\end{array}$ & 1 & 2 & 3 & 4 & 5 \\
\hline $\begin{array}{l}\text { 24. Has difficulty keeping things in mind while he/she is } \\
\text { doing something else }\end{array}$ & 1 & 2 & 3 & 4 & 5 \\
\hline
\end{tabular}




\section{APPENDIX B}

Tayside Children's Sleep Questionnaire

Question 1:

\begin{tabular}{|c|c|c|c|c|}
\hline 0 & 1 & 2 & 3 & 4 \\
$<15 \mathrm{~min}$ & $15-30 \mathrm{~min}$ & $30-45 \mathrm{~min}$ & $45-60 \mathrm{~min}$ & $>60 \mathrm{~min}$ \\
\hline
\end{tabular}

Questions 2-10:

\begin{tabular}{|c|c|c|c|c|}
\hline 0 & 1 & 2 & 3 & 4 \\
$\begin{array}{c}\text { The sleep } \\
\text { behavior never } \\
\text { occurs }\end{array}$ & $\begin{array}{c}\text { The problems } \\
\text { occur once or } \\
\text { twice a month }\end{array}$ & $\begin{array}{c}\text { Occurs once or } \\
\text { twice a week }\end{array}$ & $\begin{array}{c}\text { Occurs } \\
\text { between three } \\
\text { and five nights } \\
\text { a week }\end{array}$ & $\begin{array}{c}\text { The sleep } \\
\text { problem } \\
\text { happens every } \\
\text { night }\end{array}$ \\
\hline
\end{tabular}

\begin{tabular}{|l|c|c|c|c|c|}
\hline $\begin{array}{l}\text { 1. How long after going to bed does your child usually } \\
\text { fall asleep? }\end{array}$ & 0 & 1 & 2 & 3 & 4 \\
\hline 2. The child goes to bed reluctantly & 0 & 1 & 2 & 3 & 4 \\
\hline $\begin{array}{l}\text { 3. The child has difficulty getting to sleep at night (and } \\
\text { may require a parent to be present) }\end{array}$ & 0 & 1 & 2 & 3 & 4 \\
\hline 4. The child does not fall asleep in his or her own bed & 0 & 1 & 2 & 3 & 4 \\
\hline 5. The child wakes up two or more times in the night & 0 & 1 & 2 & 3 & 4 \\
\hline $\begin{array}{l}\text { 6. After waking up in the night, the child has difficulty } \\
\text { falling asleep again by himself or herself }\end{array}$ & 0 & 1 & 2 & 3 & 4 \\
\hline $\begin{array}{l}\text { 7. The child sleeps in the parent's bed at some time } \\
\text { during the night }\end{array}$ & 0 & 1 & 2 & 3 & 4 \\
\hline $\begin{array}{l}\text { 8. If the child wakes, he or she uses a comforter (e.g. } \\
\text { Dummy) and requires a parent to replace it }\end{array}$ & 0 & 1 & 2 & 3 & 4 \\
\hline $\begin{array}{l}\text { 9. The child wants a drink during the night (including } \\
\text { breast of bottle-feed) }\end{array}$ & 0 & 1 & 2 & 3 & 4 \\
\hline 10. Do you think your child has sleeping difficulties? & 0 & 1 & 2 & 3 & 4 \\
\hline
\end{tabular}

